\title{
Thermal performance analysis of a residential house equipped with Phase Change Material
}

\author{
Ayoub GOUNNI*1, Hasna LOUAHLIA*1 \\ ${ }^{I}$ NORMANDIE UNIV, UNICAEN, LUSAC, Site universitaire Bellevue, 120 rue de l'Exode, 50000 Saint-Lô, France
}

\begin{abstract}
In the objective to enhance the thermal inertia of the light envelopes, the integration of the phase change materials in these envelopes is suggested. This work reports the results of a numerical study to qualitatively and quantitatively investigate the thermal performance of a residential house built in France and equipped with Phase Change Materials. The impacts of Phase Change Materials (PCMs) equipped in a residential house on heating loads and the indoor comfort are analyzed by means of dynamic simulation using TRNSYS software. Thermal performance of the PCMs are assessed by comparison to a reference case identical to the PCM house but without the PCM layer. The results show that the PCMs have a remarkable effect on the indoor air temperature, thermal comfort and thermal load of the house compared to the reference house. The integration of the PCMs to the building, leads to better thermal comfort conditions compared to the conventional case. A reduction of $52.28 \mathrm{kWh} / \mathrm{m} / \mathrm{an}$ is reached when integrating the PCM layer.
\end{abstract}

\section{Introduction}

The building sector is a key component for a global low-carbon future and excessive use of energy. It is the largest contributor to the energy consumption in the worldwide scale. In Europe, commercial and residential buildings account for $38.7 \%$ of the total energy consumption 12. As a result, energy certification of buildings is one of the core measures being promoted under the policy to monitor and reduce energy consumption. This push the international scientific community towards more effective energy performance of building. According to the International Energy Agency (IEA), Energy in the Buildings and Communities Program (EBC), the key parameters that influence the energy consumption can be summarized as following: (i) climatic context, (ii) building envelop, (iii) energy systems for HVAC, (iv) occupant behavior, and (v) indoor design criteria for thermal comfort. Most of the energy consumption in buildings is related to heating and cooling systems, of which, 10-20\% is related to ventilation and air conditioning equipment.

The use of Phase Change Materials in the building envelop can help to achieve the desired reduction. The use of the latent heat absorption phenomenon associated with melting of a suitable PCM can be considered an effective way to delay or modify the temperature rise of a surface subjected to high and intermittent heat fluxes. As described in several comprehensive reviews3-5 published in the open literature, PCMs have been widely proposed for thermal storage applications due to their capability of storing and releasing large amounts of energy with a small PCM volume and a relatively low temperature variation.

There is a wide variety of PCMs with different melting point ranges, which are divided into three general categories containing organics, inorganics, and eutectics 6. The use of PCM-TES systems, passively or actively, in buildings leads to the temperature controlling and reducing the energy consumptions. These materials are applied in buildings to store and release cold and heat temperatures, with a melting point within the human com-fort range (between $15^{\circ} \mathrm{C}$ and $30^{\circ} \mathrm{C}$ )67. The PCMs are used in buildings with different methods; they can be integrated into the building's materials for use in buildings envelopes such as wallboards, walls, floors, roofs, suspended ceilings, windows as passive heating and cooling system for increasing the thermal mass. In fact, the use of PCM-TES as a passive system, in order to adjust the inner temperature, would reduce the use of the mechanical ventilation 77 .

The Phase Change Materials (PCMs) can enhance the thermal mass of the building by storing the heat coming from the exterior or the internal gain for later use. It is well documented, that the integration of the PCM in building wall can reduce the heating and cooling loads. Gounni et al.9 summarized the techniques on how the PCM can be integrated in building envelop which can be either direct immersion or micro-encapsulation. The immersion direct presents the risk of leakage phenomenon when the PCM is in liquid state, which is not good for long-term use10. However, the micro-

\footnotetext{
*Corresponding author: gounni.ayoub@gmail.com; hasna.louahlia@unicaen.fr
} 
encapsulation is preferred because it overcomes the problem of the leaking of the PCM from the surface. To be suitable for the integration into building envelop, PCM can be microencapsulated in sheets laminated with aluminum 11 .

\section{Thermo-physical properties of the PCM layer}

In order to enhance the thermal mass of the cob house, we propose here to integrate a PCM layer. We used an organic paraffin called ENERGAIN, which is constituted of $60 \%$ of microencapsulated paraffin within a copolymer. Erreur! Source du renvoi introuvable. shows the final form of the composite PCM of $5 \mathrm{~mm}$ thickness. The density of the panel is about $850 \mathrm{~kg} / \mathrm{m} 3$. The heat conductivity has been measured using guarded hot plat apparatus, which is $0.18 \mathrm{~W} / \mathrm{m} . \mathrm{K}$ for liquid phase and $0.22 \mathrm{~W} / \mathrm{m} . \mathrm{K}$ for solid phase. The heat capacity is a function of temperature, which is measured by means of a differential scanning calorimeter as presented in Fig. 1. Since the PCM is not pure material, there is two curves one of the freezing and the other one of the heating.

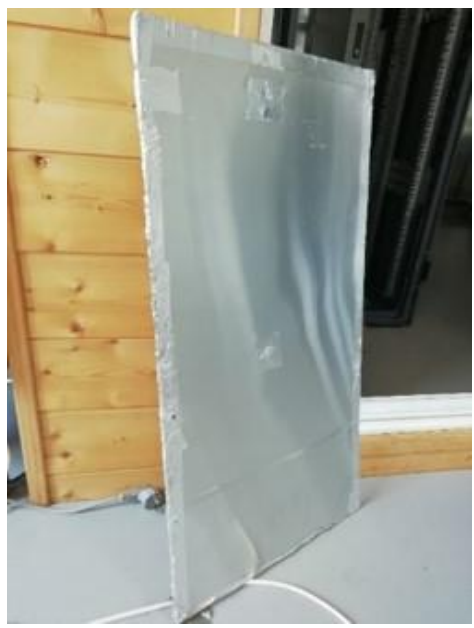

Fig. 1. PCM panel

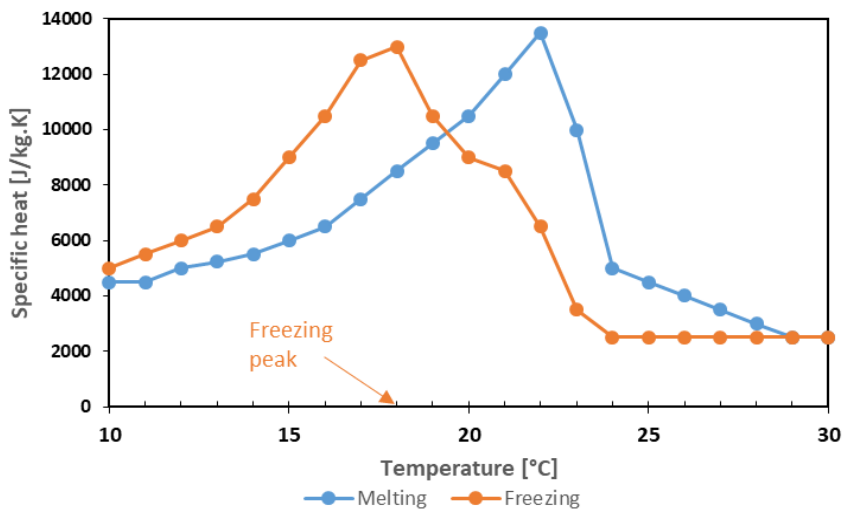

Fig. 1. PCM heat capacity Measurement

\section{Building description}

The studied building is a construction of one floor of $2.5 \mathrm{~m}$ height, located at La Manche, France. The 2D and 3D architectural plans of a single-family house are seen in Fig. 2 and Fig. 3.

The composition and thermo-physical properties of external walls are seen in

Table 1 and

Table 2. Two construction scenarios are investigated based on the building envelope composition. The first one is based on conventional building materials without PCM; while the second scenario is integrating PCM layer.
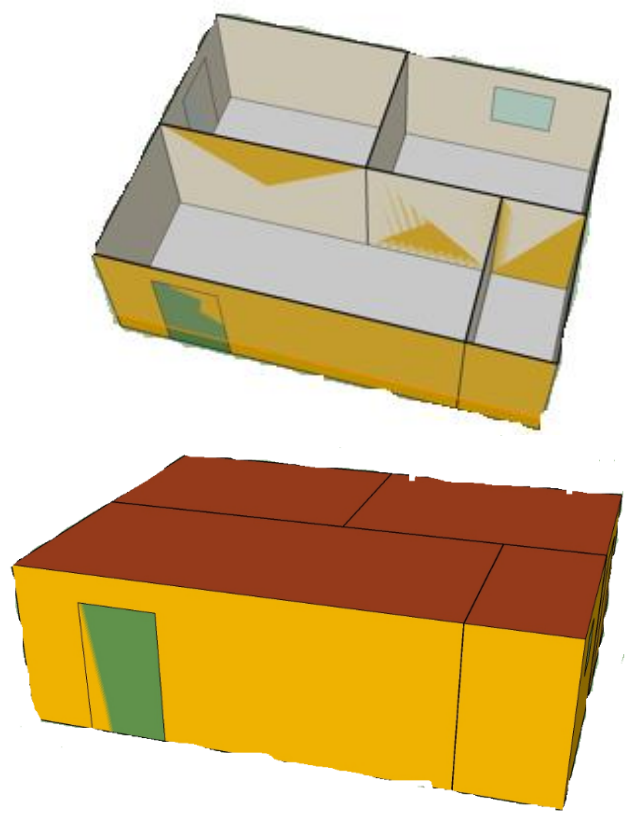

Fig. 2. 3D Architectural plans of the studied house.
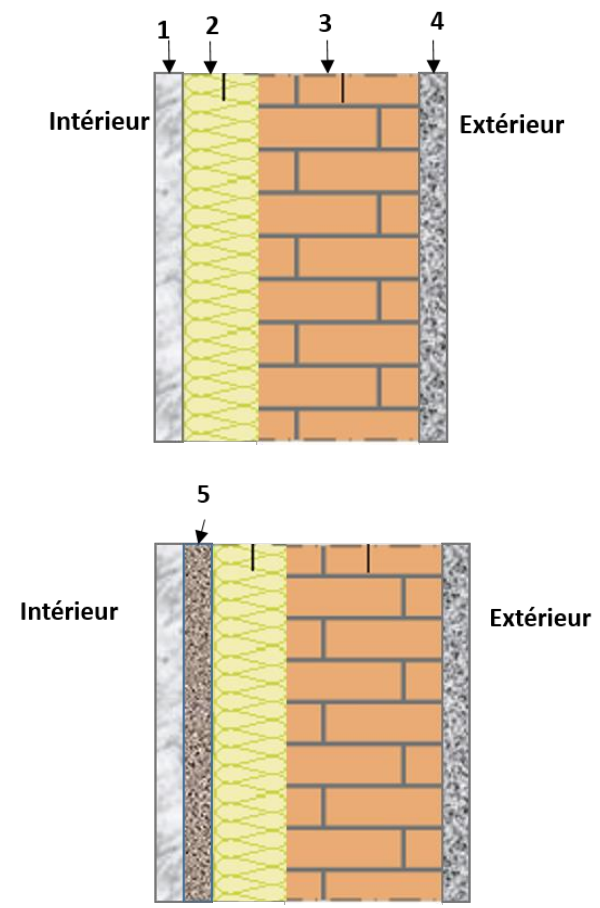

Fig. 3.Composition of the external wall ; left: with PCM ; Right: Without PCM. 1:BA13; 2:Rock wool; 3:Concrete block; 4:Mortar; 5: PCM layer 
Fig. 4. Thermal performance of the house with and without PCM layer.

Table 1. Composition of the external wall without PCM layer

\begin{tabular}{|c|c|c|c|c|}
\hline Layers & $\begin{array}{c}\text { Thickness } \\
(\mathrm{mm})\end{array}$ & $\begin{array}{c}\text { Thermal } \\
\text { conductivity } \\
(\mathrm{kJ} / \mathrm{h} . \mathrm{m} . \mathrm{k})\end{array}$ & $\begin{array}{c}\text { Calorific } \\
\text { capacity } \\
(\mathrm{kJ} / \mathrm{kg} . \mathrm{K})\end{array}$ & $\begin{array}{c}\text { Density } \\
(\mathrm{kg} / \mathrm{m} 3)\end{array}$ \\
\hline BA13 & 13 & 0.9 & 1 & 900 \\
\hline $\begin{array}{c}\text { Rock } \\
\text { wool }\end{array}$ & 100 & 0.17 & 1.03 & 150 \\
\hline $\begin{array}{c}\text { Concrete } \\
\text { block }\end{array}$ & 200 & 1.87 & 1 & 1500 \\
\hline Mortar & 15 & 4.68 & 1 & 2000 \\
\hline
\end{tabular}

Table 2. Composition of the external wall with PCM layer

\begin{tabular}{|c|c|c|c|c|}
\hline Layers & $\begin{array}{c}\text { Thickness } \\
(\mathrm{mm})\end{array}$ & $\begin{array}{c}\text { Thermal } \\
\text { conductivity } \\
(\mathrm{kJ} / \mathrm{h} . \mathrm{m} . \mathrm{k})\end{array}$ & $\begin{array}{c}\text { Calorific } \\
\text { capacity } \\
(\mathrm{kJ} / \mathrm{kg} . \mathrm{K})\end{array}$ & $\begin{array}{c}\text { Density } \\
(\mathrm{kg} / \mathrm{m} 3)\end{array}$ \\
\hline BA13 & 13 & 0.9 & 1 & 900 \\
\hline $\begin{array}{c}\text { PCM } \\
\text { layer }\end{array}$ & 50 & 0.50 & 1 & 900 \\
\hline $\begin{array}{c}\text { Rock } \\
\text { wool }\end{array}$ & 100 & 0.17 & 1.03 & 150 \\
\hline $\begin{array}{c}\text { Concrete } \\
\text { block }\end{array}$ & 200 & 1.87 & 1 & 1500 \\
\hline Mortar & 15 & 4.68 & 1 & 2000 \\
\hline
\end{tabular}

\section{Results and discussion}

\subsection{Thermal performance of the house}

Thermal behaviour of house is analysed in terms of indoor air temperature. Fig. 4 presents the hourly variation of indoor air temperature profile for both houses (Reference and PCM). From the figure, it is shown that the indoor air temperature of the PCM house has a low oscillation for all zones, this occurs because of the high thermal storage capacity of the PCM layer. This temperature difference between the Reference and PCM house will affect the heat loads, which will be investigated in the next section according to each climatic zone.

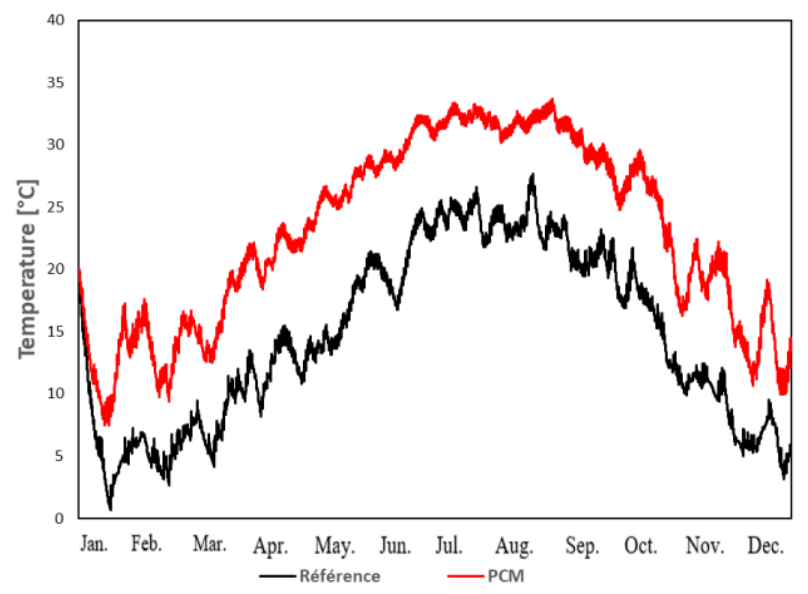

\subsection{Energetic analysis}

In this section, the inside air temperature of each zone and for the two studied configurations (i.e. Reference and PCM house) is kept at set points according to the Figure 5 for heating period in order to compute the annual thermal loads for heating. For the weekdays, the indoor air temperature is kept at $18^{\circ} \mathrm{C}$ from $00 \mathrm{~h}$ to $08 \mathrm{~h}$ and from $18 \mathrm{~h}$ to $00 \mathrm{~h}$, which corresponds to the occupancy period, while it is kept at $12^{\circ} \mathrm{C}$ from $08 \mathrm{~h}$ to $18 \mathrm{~h}$ when the house is unoccupied. Fig. 7 shows a comparison of annual heating loads of each zone of the two houses. A clear reduction on heating loads is performed by PCM house. The total heating loads related to whole house are 71.94 and 19.66 $\mathrm{kWh} / \mathrm{m}^{2} /$ year, respectively for the reference and Cob houses.



Fig. 6: weekly occupation scenarios.

Annual loads (kWh/m²/year)

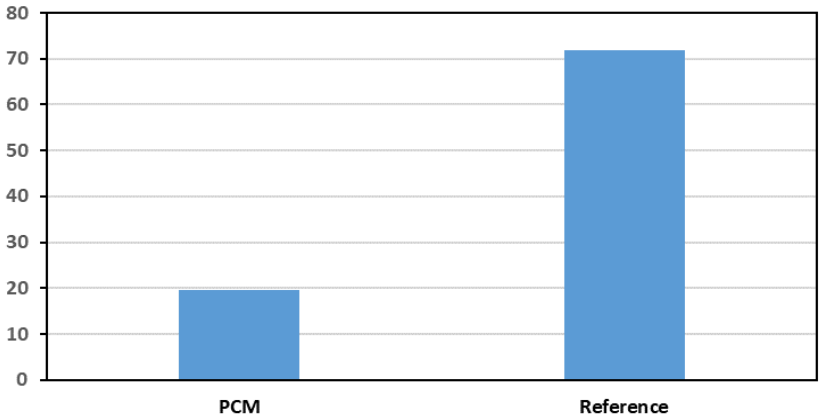

Fig. 7: Heating loads of the reference house and PCM house

Erreur! Source du renvoi introuvable. presents the fraction of phase change of the PCM during all year and the temperature of the PCM. Notice that the range of phase change is between $18{ }^{\circ} \mathrm{C}$ and $22^{\circ} \mathrm{C}$. We note that when the temperature of the PCM exceed the phase change interval the PCM is in its liquid state; and when it is lower that the phase change interval, the PCM is in solid state. It is showed that in summer, the PCM is all time in solid state which will doesn't affect the loads reduction. However, in winter period, most of the time, the PCM temperature is in the interval of the phase change which affect significantly the heating loads. 


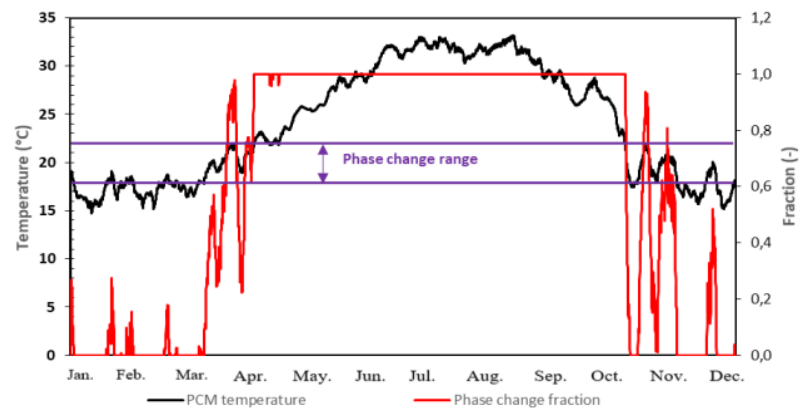

Fig. 8: Fraction of phase change according to the PCM temperature.

\section{Conclusions}

The impacts of Phase Change Materials (PCMs) equipped in a residential house on heating loads and the indoor comfort are analyzed by means of dynamic simulation using TRNSYS software. Thermal performance of the PCMs are assessed by comparison to a reference case identical to the PCM house but without the PCM layer. The results show that the PCMs have a remarkable effect on the indoor air temperature, thermal comfort and thermal load of the house compared to the reference house. The integration of the PCMs to the building, leads to better thermal comfort conditions compared to the conventional case. A reduction of 52.28 $\mathrm{kWh} / \mathrm{m}^{2} /$ an is reached when integrating the PCM layer.

\section{Acknowledgments}

The authors of this work would like to thank the Normandy region and Conseil départemental de la manche (CD50) for the funding of this work which is integrated in the regional project FIVATHE.

\section{References}

1. E. Annunziata, M. Frey, F. Rizzi, Energy 57 (2013) $125-133$.

2. J. Laustsen, International Energy Agency (IEA),2008, pp. 477-488.

3. B. Zalba, J.M. Marìn, L.F. Cabeza, H. Mehling, Appl.Therm. Eng. 23 (2003) 251-283.

4. A. Sharma, V.V. Tyagi, C.R. Chen, D. Buddhi, Renew. Sustain. Energy Rev. 13(2009) 318-345.

5. F. Agyenim, N. Hewitt, P. Eames, M. Smyth, Renew. Sustain Energy Rev. 14 (2010) 615-628.

6. V. Butala, U. Stritih, Energy Build. 41 (3) (2009) 354-359.

7. V.A.A. Raj, R. Velraj, Renew. Sustain. Energy Rev. 14 (9) (2010) 2819-2829.

8. A. de Gracia, L.F. Cabeza, Energy Build. 103 (2015) 414-419.

9. Gounni and El Alami (2017). Applied Thermal Engineering, 127, 1488-1494.

10. Xu. Wang, Yu. Hang, Lu. Li, Mei Zhao, Energy Build. 128 (15) (September 2016) 567-574.

11. K.O. Lee, M.A. Medina, E. Raith, X. Sun, Appl. Energy 137 (2015) 699-706. 